\title{
HUBUNGAN DUKUNGAN KELUARGA TERHADAP PERAWATAN KAKI UNTUK MENCEGAH KAKI DIABETIK PADA PASIEN DM TIPE 2 DI RSUD UNGARAN
}

\author{
Ismonah $^{1}$, Anita Putri Octaviani ${ }^{2}$
}

\begin{abstract}
Diabetes Mellitus (DM) is one of the chronic diseases that can cause various complications, one of which is diabetic foot wounds. In minimizing these complications, there is a need for adherence from DM patients to perform foot care. One that plays a role in influencing the adherence of DM patients to foot care is family support. This study aims to determine the relationship of family support for foot care to prevent diabetic foot in type 2 DM patients in Ungaran Hospital. The method used was cross sectional, with 30 respondents determined by purposive sampling technique. The results showed good family support as many as 18 respondents (60\%) and enough foot care as many as 23 respondents $(76.7 \%)$. The results of the Fisher test showed an association of family support for foot care in type 2 DM patients in Ungaran Hospital with ( $p$ value $=0.001$ ). Based on the results of the study, it is expected that nurses in hospitals can involve families in improving the behavior of patients in doing foot care and increasing knowledge about DM in patients and families.
\end{abstract}

Keywords: family support, foot care, type 2 DM

\section{PENDAHULUAN}

Diabetes melitus (DM) merupakan salah satu penyakit tidak menular dan kronis yang sering terjadi karena kurangnya produksi insulin oleh pankreas atau tubuh tidak mampu menggunakan insulin yang ada secara efektif (Sari, 2015).

Data yang diperoleh dari Internasional Diabetes Federation (IDF) tahun 2017 Indonesia menduduki peringkat ke-6 dunia dengan jumlah penyandang diabetes melitus sebesar 10,3 juta jiwa. Komplikasi yang paling sering dialami oleh pasien DM adalah luka kaki diabetik yang apabila tidak segera ditangani akan semakin parah sehingga memerlukan tindakan amputasi untuk menghilangkan jaringan yang terinfeksi serta menyelamatkan anggota tubuh lain, dan nyawa pasien (Rudystina, 2017).

Salah satu cara yang dapat dilakukan oleh pasien DM agar terhindar dari komplikasi luka kaki diabetik dengan melakukan perawatan kaki (Tarwoto, et al., 2012). Penelitian yang dilakukan oleh Amelia (2018) menunjukkan bahwa sebanyak (43,47\%) responden yang melakukan perawatan kaki dengan baik memiliki sensasi kaki normal sehingga dapat mengurangi resiko gangguan sensorik pada kaki.

Salah satu faktor yang berperan dalam mempengaruhi kepatuhan pasien DM dalam menjalani perawatan kaki adalah dukungan keluarga (Wardani dan Isfaniari, 2014). Penelitian yang dilakukan oleh Prawesti dan Ratnawati (2015) menunjukkan bahwa dukungan keluarga sangat berperan dalam upaya pencegahan (perawatan kaki). Tetapi penelitian yang dilakukan oleh Mailangkay, Katuuk, dan Karundeng (2017) menunjukkan bahwa tidak ada hubungan yang signifikan antara dukungan keluarga 
dengan perawatan kaki mandiri pada pasien diabetes melitus tipe 2 .

Berdasarkan latar belakang dan penelitian terkait maka peneliti tertarik untuk melakukan penelitian tentang hubungan dukungan keluarga terhadap perawatan kaki untuk mencegah kaki diabetik pada pasien DM tipe 2 di RSUD Ungaran.

\section{TUJUAN PENELITIAN}

Untuk mengetahui tentang hubungan dukungan keluarga terhadap perawatan kaki untuk mencegah kaki diabetik pada pasien DM tipe 2 di RSUD Ungaran.

\section{METODE/DESAIN PENELITIAN}

Penelitian ini menggunakan pendekatan cross sectional untuk mengetahui hubungan dukungan keluarga terhadap perawatan kaki pada pasien DM tipe 2 di RSUD Ungaran. Alat pengumpulan data yang digunakan dalam penelitian ini adalah kuesioner dukungan keluarga yang diadopsi dari Fatimah (2016) dan kuesioner perawatan kaki yang diadopsi dari Diani (2013). Data yang telah terkumpul kemudian dianalisa menggunakan uji statistik yaitu uji Fisher.

\section{POPULASI, SAMPEL, DAN} TEKNIK SAMPLING

Berdasarkan hasil studi pendahuluan yang dilakukan di RSUD Ungaran jumlah pasien DM tipe 2 pada tahun 2018 sebanyak 314 maka jumlah sampel yang digunakan pada penelitian ini sebanyak 30 responden yang ditetapkan dengan teknik purposive sampling.
HASIL PENELITIAN

Pada penelitian ini mendapatkan hasil sebagai berikut:

\section{Tabel 1.}

Distribusi frekuensi jenis kelamin, usia, pendidikan, lama menderita DM, pekerjaan, penyakit penyerta, dukungan keluarga dan perawatan kaki pada pasien DM tipe 2 di RSUD Ungaran $(n=30)$

\begin{tabular}{|c|c|c|}
\hline Karakteristik & \multirow[t]{2}{*}{ (n) } & \multirow[t]{2}{*}{$(\%)$} \\
\hline 1. Jenis Kelamin & & \\
\hline Laki-laki & 8 & 26,7 \\
\hline Perempuan & 22 & 73,3 \\
\hline \multicolumn{3}{|l|}{ 2. Usia } \\
\hline $36-45$ tahun & 2 & 6,7 \\
\hline $46-55$ tahun & 11 & 36,7 \\
\hline 56-65 tahun & 9 & 30,0 \\
\hline$>65$ tahun & 8 & 26,7 \\
\hline \multicolumn{3}{|l|}{ 3. Pendidikan } \\
\hline SD & 10 & 33,3 \\
\hline SMP & 11 & 36,7 \\
\hline SMA & 6 & 20,0 \\
\hline Perguruan & 2 & 6,7 \\
\hline Tinggi (PT) & & \\
\hline Tidak Sekolah & 1 & 3,3 \\
\hline \multirow{2}{*}{\multicolumn{3}{|c|}{$\begin{array}{l}\text { 4. Lama Menderita } \\
\text { DM }\end{array}$}} \\
\hline & & \\
\hline$<1$ tahun & 3 & 10,0 \\
\hline 1-5 tahun & 9 & 30 \\
\hline$>5$ tahun & 18 & 60 \\
\hline \multicolumn{3}{|l|}{ 5. Pekerjaan } \\
\hline Swasta & 11 & 36,7 \\
\hline Pensiun & 4 & 13,3 \\
\hline IRT & 15 & 50,0 \\
\hline PNS & 0 & 0 \\
\hline \multicolumn{3}{|l|}{ 6. Penyakit } \\
\hline Penyerta & & \\
\hline Hipertensi & 16 & 53,3 \\
\hline Stroke & 4 & 13,3 \\
\hline Tidak ada & 10 & 33,3 \\
\hline \multicolumn{3}{|l|}{ 7. Dukungan } \\
\hline Keluarga & & \\
\hline Kurang & 12 & 40,0 \\
\hline Baik & 18 & 60,0 \\
\hline \multicolumn{3}{|l|}{ 8. Perawatan Kaki } \\
\hline Kurang & 4 & 13,3 \\
\hline Cukup & 23 & 76,7 \\
\hline Baik & 3 & 10,0 \\
\hline
\end{tabular}


Tabel 2.

Distribusi dukungan keluarga terhadap perawatan kaki pada pasien DM tipe 2 di RSUD Ungaran

$$
(n=30)
$$

\begin{tabular}{|c|c|c|c|c|}
\hline \multirow[b]{2}{*}{$\begin{array}{c}\text { Dukungan } \\
\text { Keluarga }\end{array}$} & \multicolumn{2}{|c|}{ Perawatan Kaki } & \multirow{2}{*}{$\begin{array}{c}\text { Total } \\
\mathrm{n}\end{array}$} & \multirow{2}{*}{$\begin{array}{l}P- \\
\text { value }\end{array}$} \\
\hline & Kurang & Baik & & \\
\hline Kurang & $\begin{array}{c}8 \\
(88,9 \%)\end{array}$ & $\begin{array}{c}4 \\
(19,0 \%)\end{array}$ & $\begin{array}{c}12 \\
(40 \%)\end{array}$ & \\
\hline Baik & $\begin{array}{c}1 \\
(11,1 \%)\end{array}$ & $\begin{array}{c}17 \\
(81,0 \%)\end{array}$ & $\begin{array}{c}18 \\
(60 \%)\end{array}$ & 0,001 \\
\hline Total & $\begin{array}{c}9 \\
(100 \%)\end{array}$ & $\begin{array}{c}21 \\
(100 \%)\end{array}$ & $\begin{array}{c}30 \\
(100 \%)\end{array}$ & \\
\hline
\end{tabular}

\section{PEMBAHASAN}

Hasil penelitian yang dilakukan pada 30 responden yang mengalami DM tipe 2 di RSUD Ungaran menunjukkan bahwa sebagian besar berjenis kelamin perempuan sebanyak 22 responden $(73,3 \%)$. Menurut Tamara, Bayhakki, dan Nauli (2014) DM tipe 2 pada perempuan terjadi karena adanya penurunan hormon estrogen akibat menopause.

Sebagian besar pasien yang mengalami DM tipe 2 adalah lansia awal (46-55 tahun) sebanyak 11 responden (36,7\%). Menurut Quamila (2018) pada usia lansia (45-64 tahun) resistensi insulin dan kerja insulin akan mengalami penurunan karena faktor degeneratif sehingga akan menurunkan fungsi tubuh dalam melakukan metabolisme glukosa darah sehingga rentan mengalami berbagai macam penyakit seperti DM.

Pendidikan yang ditempuh oleh responden sebagian besar adalah SMP sebanyak 11 responden (36,7\%). Menurut Hakim (2018) semakin tinggi tingkat pendidikan pasien maka akan melakukan pencegahan dengan baik dibandingkan pada pasien dengan pendidikan rendah karena pendidikan merupakan dasar utama keberhasilan dalam pengobatan.
Tetapi terdapat penelitian yang menunjukkan bahwa DM dapat terjadi pada berbagai jenjang pendidikan, karena pendidikan bukan merupakan faktor utama terjadinya DM.

Hasil penelitian menunjukkan sebagian besar responden sudah mengalami DM tipe $2>5$ tahun sebanyak 18 responden (60\%). Pada pasien yang lama menderita DM maka akan banyak mendapat edukasi yang diberikan oleh tenaga kesehatan, sehingga dapat meningkatkan pengetahuan dan pemahamannya tentang DM (Isnaini dan Ratnasari, 2018).

Responden yang mengalami DM sebagian besar bekerja sebagai ibu rumah tangga sebanyak 15 responden $(50,0 \%)$. Sebagaimana dikutip oleh Sukmaningsih (2016) jenis pekerjaan dapat berperan dalam timbulnya penyakit dari ada atau tidaknya aktivitas fisik didalam pekerjaan. Ibu rumah tangga lebih beresiko karena kurangnya aktivitas yang dilakukan akan beresiko mengalami retensi insulin.

Penyakit penyerta terbanyak yaitu hipertensi sebanyak 16 responden $(53,3 \%)$. Pada pasien yang mengalami DM dapat terjadi kerusakan pembuluh darah dan peningkatan penumpukan lemak pada dinding pembuluh darah akan menyebabkan jantung bekerja lebih keras dalam memompa darah. Kodisi inilah yang lama-lama akan menyebabkan hipertensi pada pasien DM (Joseph, 2018).

Berdasarkan hasil uji Fisher didapatkan hasil $p$-value $=0,001$ yang artinya terdapat hubungan yang signifikan antara dukungan keluarga terhadap perawatan kaki. Dari penelitian ini menunjukkan pasien memiliki dukungan keluarga yang baik ditunjukkan dengan selalu diingatkan untuk melakukan kontrol kesehatan dan pengaturan pola makan serta selalu menjaga kebersihan kaki. Hasil penelitian ini 
menunjukkan jumlah pasien yang mendapat dukungan keluarga baik dan melakukan perawatan kaki dengan baik sebanyak 17 responden (81\%), yang artinya dengan adanya dukungan keluarga yang baik maka perilaku perawatan kaki yang dilakukan oleh pasien tersebut juga akan baik. Hasil penelitian ini sejalan dengan yang dilakukan oleh Rembang, Katuuk, dan Malara (2017) menunjukkan adanya dukungan sosial keluarga yang baik akan mampu meningkatkan kemampuan pasien dalam melakukan perawatan kaki.

Sementara pada penelitian ini terdapat pasien yang kurang dukungan keluarga tetapi mampu melakukan perawatan kaki baik sebanyak 4 responden (19\%). Kondisi tesebut menunjukkan bahwa terdapat faktor lain yang dapat mempengaruhi pasien dalam melakukan perawatan kaki. Menurut Amalia (2012) faktor lain yang dapat meningkatkan kemampuan pasien dalam melakukan perawatan kaki seperti faktor pengetahuan, kemauan dan kemampuan dalam melakukan perawatan secara mandiri serta sumber informasi. Menurut Windasari, Wibowo, dan Afandi (2018) sumber informasi yang diperoleh pasien DM akan meningkatkan pengetahuan dan informasi sehingga dapat melakukan perawatan dengan tepat dalam upaya pencegahan terjadinya komplikasi.

Memberikanpenjelasanlebihlanjut, dalam Notoadmojo (2010), adanya hubungan antara dukungan keluarga dengan kemandirian lansia dengan bantuan dan pendampingan keluarga akan mudah melakukan kemandiriannya dalam kehidupan sehari-hari karena lansia merasa diperhatikan sehingga tercapai kemandirian yang baik, dengankemandirian yang baikterutamadalamperawatan kaki, makapasienakantercegahdarikompli kasi kaki dan luka.

\section{KESIMPULAN}

1. Berdasarkan penelitian yang dilakukan di RSUD Ungaran didapatkan hasil karakteristikrespondenbahwa sebagian besar pasien DM tipe 2 berjenis kelamin perempuan sebanyak 22 responden $(73,3 \%)$, terjadi pada usia lansia awal (4655 tahun) sebanyak 11 responden (36,7\%), berpendidikan SMP sebanyak 11 responden $(36,7 \%)$, mengalami DM tipe $2>5$ tahun sebanyak 18 responden (60\%), bekerja sebagai ibu rumah tangga sebanyak 15 responden (50\%), penyakit penyerta yang sebagian besar dialami adalah hipertensi sebanyak 16 responden (53,3\%).

2. Berdasarkan penelitian yang dilakukan di RSUD Ungaran didapatkan hasil bahwa sebagian besar pasien DM tipe 2 memiliki dukungan keluarga yang baik yaitu sebanyak 18 responden $(60 \%)$ dan perawatan kaki yang dilakukan dalam kategori cukup yaitu sebanyak 23 responden $(76,7 \%)$

3. Berdasarkan hasil penelitian yang dilakukan menunjukkan adanya hubungan dukungan keluarga terhadap perawatan kaki untuk mencegah kaki diabetik pada pasien DM tipe 2 di RSUD Ungaran dengan ( $p$-value $=0,001<0,05$ ).

\section{SARAN}

1. Diharapkan perawat yang ada di rumah sakit melibatkan keluarga dalam meningkatkan perilaku pasien dalam melakukan perawatan kaki serta meningkatkan pengetahuan tentang DM pada pasien dan keluarga.

2. Diharapkan institusi dapat memberikan gambaran mengenai 
hubungan dukungan keluarga terhadap perawatan kaki untuk mencegah kaki diabetik pada pasien DM tipe 2.

3. Diharapkan bagi peneliti selanjutnya dapat meneliti lebih lanjut dengan menggunakan hasil penelitian ini sebagai informasi dan masukan mengenai dukungan keluarga terhadap perawatan kaki pada pasien DM tipe 2 yang dapat meningkatkan kesadaran pasien dalam mencegah terjadinya komplikasi terutama dalam pencegahan kaki diabetik terutama dalam upaya meningktakan pengetahuan mengenai DM pada pasien maupun keluarga pasien.

\section{DAFTAR PUSTAKA}

Amalia, W. C., Sutikno, E., dan Nugraheni, R. 2012. Hubungan Tingkat Pengetahuan tentang Diabetes Mellitus dan Gaya Hidup dengan Tipe Diabetes Mellitus di Puskesmas Wonodadi Kabupaten Blitar. Jurnal Preventia. 1. (1). 14-19

Amelia, R. 2018. Hubungan Perilaku Perawatan Kaki dengan Terjadinya Komplikasi Luka Kaki Diabetes pada Pasien Diabetes Melitus Tipe 2 di Puskesmas Tuntungan Kota Medan. Talenta Conference Series: Tropical Medicine.1. (1)

Diani, N. 2013. Pengetahuan dan Praktik Perawatan Kaki pada Klien Diabetes Melitus Tipe 2 di Kalimantan Selatan. Tesis: Universitas Indonesia, Jakarta.

Fatimah. 2016. Hubungan Faktor Personal dan Dukungan Keluarga dengan Manajemen Diri Penderita Diabetes Melitus di Posbindu Wilayah Kerja Puskesmas Pisangan Kota Tangerang Selatan. Skripsi: Universitas Islam Negeri Syarif Hidayatullah.

Hakim, D. L. 2018. Hubungan Tigkat Sosial Ekonomi: Pendidikan,
Penghasilan, dan Fasilitas dengan Penceghan Komplikasi Kronis pada Penyandang Diabetes Melitus Tipe 2 di Surakarta. Skripsi: Universitas Muhammadiyah Surakarta, Surakarta.

International Diabetes Federation. 2017.

http://diabetesatlas.org/resource $\mathrm{s}$

Isnaini, N., dan Ratnasari. 2018. Faktor Risiko Mempengaruhi Kejadian Diabetes Melitus Tipe 2. Jurnal Keperawatan dan Kebidanan Aisyah. 1. (14).59-66 Joseph, N. 2018. Orang yang Punya Diabetes Harus Waspada dengan Risiko Kena Hipertensi. https://hellosehat.com/pusatkesehatan/hipertensi-tekanandarah-tinggi/hubungandiabetes-dan-hipertensi/.

Mailangkay, S., Katuuk, M. E., dan Karundeng, M. 2017. Hubungan Motivasi dan Dukungan Keluarga dalam Perawatan Kaki Mandiri pada Pasien Diabetes Melitus Tipe . Jurnal keperawatan. $\quad 5 . \quad$ (1). https://ejournal.unsrat.ac.id/inde x.php/jkp/article/view/14716.

Notoatmodjo, S. 2010. Metodologi Penelitian Kesehatan. Rineka Cipta. Jakarta

Prawesti, D., dan Ratnawati, D. 2015. Dukungan Keluarga Meningkatkan Upaya Pencegahan Gangren (Perawatan Kaki) pada Pasien Diabetes Melitus. Jurnal Penelitian Keperawatan. 1.(2). 165-174

Quamila, A. 2018. Usia Rata-Rata Seseorang Saat Didiagnosis Mengidap Diabetes. https://hellosehat.com/pusatkesehatan/diabetes-kencingmanis/usia-terkena-diabetesdiagnosis-diabetes/

Rembang, V. P., Katuuk. M. E., dan Malara. R. 2017. Hubungan Dukungan Sosial dan Motivasi 
dengan Perawatan Mandiri pada Pasien Diabetes Melitus Tipe 2 di Poliklinik Penyakit Dalam RSUD Mokopido ToliToli. Skripsi: Universitas Sam Ratulangi

Rudystina, A. 2017. Mengapa Penderita Diabetes Rentan Diamputasi?.https://hellosehat.c om/hidup-sehat/faktaunik/amputasi-kaki-penderitadiabetes/

Sari, Y. 2015. Perawatan Luka Diabetes. Yogyakarta: Graha IImu.

Sukmaningsih, W. R. 2016. Faktor Risiko Kejadian Diabetes Mellitus Tipe II di Wilayah Kerja Puskesmas Purwodiningratan Surakarta. Skripsi. Universitas Muhammadiyah Surakarta

Tamara, E., Bayhakki., dan Nauli, F. A. 2014. Hubungan Antara Dukungan Keluarga dan Kualitas Hidup Pasien Diabates Melitus Tipe 2 di RSUD Arifin Achmad Provinsi Riau. JOM PSIK. 1. (2). 1-7
Tarwoto., Wartonah., Taufiq, I., dan Mulyati, L. 2012.Keperawata Medikal Bedah Gangguan SistemEndokrin. Jakarta: TIM.

Wardani, A. K., dan Isfandiari, M. A. 2014. Hubungan Dukungan Keluarga dan Pengendalian Kadar Gula Darah dengan Gejala Komplikasi Mikrovaskuler. Skripsi. Universitas Airlangga

Windasari, N. N., Wibowo, S., dan Afandi, M. 2018. Pendidikan Kesehatan dalam Meningkatkan Kepatuhan Merawat Kaki pada Pasien Diabetes Mellitus Tipe II. Skripsi. STIKES Mitra Lampung.

${ }^{1}$ Dosen Program Studi S-1 Keperawatan STIKES Telogorejo Semarang

2 Alumni Program Studi S-1 Keperawatan STIKES Telogorejo Semarang 